\title{
Clinical and Dermoscopic Approaches to Diagnosis of Frontal Fibrosing Alopecia: Results From a Multicenter Study of the International Dermoscopy Society
}

Michela Starace ${ }^{1}$, Gloria Orlando ${ }^{2}$, Matilde Iorizzo ${ }^{3}$, Aurora Alessandrini ${ }^{1}$, Francesca Bruni ${ }^{1}$, Victor Desmond Mandel ${ }^{4,5}$, Kelati Awatef ${ }^{6}$, Horacio Cabo $^{7}$, Gabriella Fabbrocini ${ }^{13}$, Baybay Hanane ${ }^{8}$, Sven Lanssens ${ }^{9}$, Alejandro Lobato-Berezo ${ }^{10}$, Fatima Zahra Mernissi ${ }^{8}$, John Paoli1 ${ }^{11,12}$, Angela Patrí13 ${ }^{13}$, Emilia Noemi Cohen Sabban ${ }^{7}$, Martyna Sławińska ${ }^{14}$, Michał Sobjanek ${ }^{14}$, Oscar Zaar ${ }^{11,12}$, Giovanni Pellacani ${ }^{4,15}$, Bianca Maria Piraccini ${ }^{1}$

\footnotetext{
1 Department of Experimental, Diagnostic, and Specialty Medicine-Division of Dermatology, University of Bologna, Bologna, Italy

2 Department of Medicine - DIMED, Dermatology Unit, University of Padova, Italy

3 Private Dermatology Practice, Bellinzona, Lugano, Switzerland

4 Dermatology Unit, Surgical, Medical, and Dental Department of Morphological Sciences related to Transplant, Oncology and Regenerative

Medicine, University of Modena and Reggio Emilia, Modena, Italy

5 Dermatology Unit, Department of Clinical and Experimental Medicine, University of Parma, Parma, Italy

6 Dermatology Department, Cheikh Khalifa International University Hospital, Mohammed VI University of Health Sciences (UM6SS),

Casablanca, Morocco

7 Dermatology Division of the Instituto de Investigaciones Médicas Alfredo Lanari, University of Buenos Aires (UBA), Argentina

8 Dermatology Department, UHC Hassan II. Fez, Morocco

9 Dermatologie Maldegem - Maldegem, Belgium

10 Department of Dermatology, Hospital del Mar-Parc de Salut Mar, Barcelona, Spain

11 Department of Dermatology and Venereology, Institute of Clinical Sciences, Sahlgrenska Academy, University of Gothenburg,

Gothenburg, Sweden

12 Region Västra Götaland, Sahlgrenska University Hospital, Department of Dermatology and Venereology, Gothenburg, Sweden

13 Department of Clinical Medicine and Surgery, Section of Dermatology, University of Naples Federico II

14 Department of Dermatology, Venereology and Allergology, Faculty of Medicine, Medical University of Gdańsk, Poland

15 Dermatologic Unit, Department of Clinical Internal, Anesthesiological and Cardiovascular Sciences, Sapienza University of Rome,

Rome, Italy
}

Key words: frontal fibrosing alopecia, trichoscopy, diagnosis, non-invasive, techniques

Citation: Starace M, Orlando G, Iorizzo M, et al. Clinical and dermoscopic approaches to diagnosis of frontal fibrosing alopecia: results from a multicenter study of the international dermoscopy society. Dermatol Pract Concept. 2022; 12(1):e2022080. DOI: https://doi .org/10.5826/dpc.1201a 80

Accepted: October 18, 2021; Published: January 2022.

Copyright: $\odot 2022$ Starace et al. This is an open-access article distributed under the terms of the Creative Commons AttributionNonCommercial License (BY-NC-4.0), https://creativecommons.org/licenses/by-nc/4.0/, which permits unrestricted noncommercial use, distribution, and reproduction in any medium, provided the original authors and source are credited.

Funding: None.

Competing interests: None.

Authorship: All authors have contributed significantly to this publication.

Corresponding author: Gloria Orlando, Dermatology Unit, Department of Medicine - DIMED, University of Padova, Italy.

E-mail: gloriaorlando@gmail.com 
ABSTRACT Introduction: Frontal fibrosing alopecia (FFA) is a form of primary lymphocytic scarring alopecia characterized by a progressive recession of the fronto-temporal hairline. Although the clinical presentation of FFA is very typical, biopsy for histopathological examination is still recommended to confirm the diagnosis. Currently, a growing number of skin and mucosal inflammatory diseases are diagnosed with modern noninvasive techniques such as dermoscopy without the necessity of a biopsy.

Objectives: The International Dermoscopy Society (IDS) aimed to test the ability of its members to diagnose classic FFA through clinical and dermoscopic parameters and to compare acquired data to the largest cohort studies published since 1994.

Methods: This is an observational, cross-sectional study describing patient demographics, clinical presentation and diagnostic tools used in a sample of FFA patients collected by IDS members. A literature search was then performed using Pubmed to review studies reporting more than 100 cases.

Results: IDS members submitted 188 cases demonstrating a predominant female population (98.4\%). In $71.8 \%$ of the cases, the clinical presentation and the trichoscopic findings allowed for the diagnosis. Out of 24 revised studies, 13 showed that clinical and trichoscopic features were decisive for the diagnosis in almost all cases.

Conclusions: Demographic and clinical data of our cohort were mostly comparable to previous reported data on FFA. The relevant role of the clinical and trichoscopic features in diagnosing FFA was confirmed by our study and the reviewed literature. Trichoscopy could be considered a worldwide-acknowledged non-invasive technique for the diagnosis of FFA.

\section{Introduction}

Frontal fibrosing alopecia (FFA), first described by Kossard in $1994[1,2]$ is a form of primary lymphocytic scarring alopecia characterized by a progressive band-like recession of the fronto-temporal hairline and, in $50-75 \%$ of cases, by a partial or complete alopecia of the eyebrows. Whether FFA is only a form of lichen planopilaris (LPP) or a more complex disorder is still a matter of debate [3-5].

Thousands of cases have been described to date, with increasing incidence of the disease worldwide. Postmenopausal women are still those primarily affected, but women with childbearing potential and males can also present with this disease [6-8]. Scalp FFA can also present in atypical forms such as linear, diffuse, zig-zag, and pseudo-fringe patterns [9]. Hair follicles on the occipital scalp and sideburns can also be involved as well as eyelashes, beard, axillae, limbs and pubis [10-12]. Lichen planus pigmentosus, facial papules and facial erythema have also been described in patients with FFA indicating that this is not necessarily a disease limited to the scalp and eyebrows [13-15].

The real incidence of FFA is unknown, but the important increase in the reported cases in recent years has led some authors to refer to it as an epidemic disease [16] The etiopathogenesis and the reason for the increasing incidence of FFA are still unknown. The fact that FFA develops later in life suggests that triggering environmental factors might play a role in the development of the disease. A genetic basis has also been hypothesized since FFA has been diagnosed in siblings and members of the same family $[17,18]$. Although FFA is thought to be a variant of LPP, there is no reported association with HLA-DR1. A recent genome-wide association study showed that FFA correlates with the HLA-B*07:02 allele [19]. Lastly, it has been speculated that the disease was present even before Kossard's first description, but somehow passed unnoticed [20].

Due to the lack of randomized clinical trials and lack of a control group in previous clinical studies, treatment of FFA is not evidence-based [21]. Lack of evidence doesn't mean, however, lack of effectiveness. Disease control might be achieved with topical, intralesional and oral treatments, often combined together. The treatment aim is always to stop disease progression [22].

At present, although the clinical picture of FFA is very typical in most cases, a biopsy for histopathological confirmation is still recommended to administer the correct treatment [23]. In cases not involving the scalp, a biopsy is mandatory. Scarring might be subtle and the fibrous tracts so thin that the loss of follicular ostia might be missed. Thus, FFA can be mistaken for a nonscarring alopecia, particularly alopecia areata (AA) and androgenic alopecia (AGA). Moreover, due to the presence of the disease in cosmetically sensitive areas, patients do not always accept biopsy even if it is a $2-\mathrm{mm}$ punch biopsy [24]. For these reasons, modern noninvasive techniques including dermoscopy [25-27], reflectance confocal microscopy [28] and optical coherence tomography [29] are increasingly used to diagnose several skin and mucosal inflammatory diseases. The goal is to perform a diagnosis without the necessity of a biopsy and to reserve it only for early stages, doubtful cases and/or uncommon presentations.

Therefore, the International Dermoscopy Society (IDS) aimed to test the ability of its members to diagnose typical or classic FFA through clinical and dermoscopic parameters and compare the acquired data to the largest cohort studies published since 1994. 


\section{Methods}

The study was launched by the IDS via an online call for contributions published on the IDS website (www.dermoscopy-ids.org). From March 2018 to March 2020, IDS members were invited to submit cases of FFA. High quality clinical and dermoscopic images of the clinical presentations were mandatory. Information on patient demographics and lesion characteristics were also required including age, gender, involved skin/scalp areas, time at onset, subjective symptoms and trichoscopic features. Furthermore, information regarding the diagnostic methodologies were also mandatory. The study was conducted in accordance with ethical guidelines, and IRB approval was obtained. All data were collected and analyzed.

A literature search for "frontal fibrosing alopecia" was then performed on PubMed and returned 502 items (April 2021). Only papers reporting more than 100 cases were considered and revised. For each paper the year of publication, the number of patients, the origin of the population, the type of diagnostic methodology was collected.

\section{Results}

After the initial call, 206 FFA cases from 10 different centres were collected, but 18 cases were excluded from analysis due to misdiagnosis $(8.7 \%)$. The clinical and trichoscopic data of all 188 included cases are presented in Table 1 . The mean age of the studied population was 62 years (range 40-84) with a predominant female population $(98.4 \%)$ and only 3 male patients. The great majority of the female population were post-menopausal $(88.1 \%)$ with an average age of climacteric onset at 44.3 years. The mean age at onset of the disease was 58.6 years, on average 11.2 years after menopause. However, the disease was diagnosed up to 35 years after menopause. Regarding the degree of disease at diagnosis, $51.6 \%$ of the patients already showed grade 2 disease at that timepoint. When the frontal scalp was involved, the mean recession of the hairline was $2.35 \mathrm{~cm}(0-10 \mathrm{~cm})$ and the distance between the glabella and the forehead was $7.57 \mathrm{~cm}$ (range $5-15 \mathrm{~cm}$ ). FFA also affected the parietal regions in $70.2 \%$ of cases (132/188), while the occipital region was involved in $11.7 \%$ of cases (22/188). The sideburns were not affected in any of the patients.

Reduction or complete loss of eyebrows was reported in $85.6 \%$ of patients with partial loss in 104 patients $(55.3 \%)$ and total loss in 56 patients $(29.8 \%)$. The beard was involved only in one male patient, whereas involvement of eyelashes, armpits and pubis were reported in 52 (27.6\%), 80 (42.5\%) and $68(36.1 \%)$ patients, respectively. In all cases with an extra-scalp involvement, the eyebrows were also compromised at the same time. Non-inflammatory facial papules were observed in 56 patients $(29.8 \%)$. In 48 patients, they
Table 1. Clinical and Trichoscopy Data from 188 Patients Affected by FFA and Collected Through the International Dermoscopy Society Online Call

\begin{tabular}{|c|c|}
\hline Characteristics & \\
\hline $\begin{array}{l}\text { Age (range) } \\
\text { Female patients }\end{array}$ & $\begin{array}{l}62(40-84) \text { years } \\
98.4 \%(185 / 188)\end{array}$ \\
\hline Post-menopausal patients & $88.1 \%(163 / 185)$ \\
\hline Menopause onset, mean age (range) & $44.3(40-61)$ years \\
\hline FFA family history & $10.1 \%(19 / 188)$ \\
\hline AGA family history & $42 \%(79 / 188)$ \\
\hline AGA personal history & $38.8 \%(73 / 188)$ \\
\hline FFA onset, mean age (range) & $58.6(15-84)$ years \\
\hline Disease duration, mean (range) & $\begin{array}{l}4.4 \text { ( } 2 \text { months - } \\
30 \text { years) years }\end{array}$ \\
\hline \multicolumn{2}{|l|}{ Clinical Severity } \\
\hline Grade 1 & $37(19.6 \%)$ \\
\hline Grade 2 & $97(51.6 \%)$ \\
\hline Grade 3 & $45(23.9 \%)$ \\
\hline Grade 4 & $7(3.7 \%)$ \\
\hline Grade 5 & $2(1 \%)$ \\
\hline \multicolumn{2}{|l|}{ Clinical Data } \\
\hline Recession & $2.35(0-10) \mathrm{cm}$ \\
\hline Glabella-hairline distance & $7.57(5-15)$ \\
\hline Occipital area involvement & $11.7 \%(22 / 188)$ \\
\hline Parietal area involvement & $70.2 \%(132 / 188)$ \\
\hline Eyebrows involvement & $85.6 \%(161 / 188)$ \\
\hline Eyelashes involvement & $27.6 \%(52 / 188)$ \\
\hline Body hairs involvement & $47,3 \%(89 / 188)$ \\
\hline Armpits hairs involvement & $42.5 \%(80 / 188)$ \\
\hline Pubis hairs involvement & $36.1 \%(68 / 188)$ \\
\hline Beard (*men only*) & $33.3 \%(1 / 3)$ \\
\hline Facial papules & $29.8 \%(56 / 188)$ \\
\hline \multicolumn{2}{|l|}{ Scalp symptoms } \\
\hline Pruritus & $65.9 \%(124 / 188)$ \\
\hline Trichodynia & $22.9 \%(43 / 188)$ \\
\hline \multicolumn{2}{|l|}{ Trichoscopy } \\
\hline Empty follicles & $93.6 \%(176 / 188)$ \\
\hline Absence of follicular ostia & $92 \%(173 / 188)$ \\
\hline Perifollicular erythema & $63.8 \%(129 / 188)$ \\
\hline Follicular hyperkeratosis & $60.1 \%(113 / 188)$ \\
\hline Lonely hairs & $54.8 \%(103 / 188)$ \\
\hline \multicolumn{2}{|l|}{ Clinical associations } \\
\hline AGA & $38.8 \%(73 / 188)$ \\
\hline Lichen planopilaris & $18.6 \%(35 / 188)$ \\
\hline Lichen planus (skin/mucosae/nails) & $5.3 \%(10 / 188)$ \\
\hline \multicolumn{2}{|l|}{ Diagnostic methods } \\
\hline Dermoscopy & $71.8 \%(135 / 188)$ \\
\hline Biopsy & $28.2 \%(53 / 188)$ \\
\hline
\end{tabular}

$\mathrm{FFA}=$ frontal fibrosing alopecia; $\mathrm{AGA}=$ androgenetic alopecia 
were localized on the face, in 6 patients on the limbs and in 2 patients simultaneously on the face, limbs and trunk.

Concomitant signs of LPP on the scalp were present in 35 patients $(18.6 \%)$. Five of them showed diffuse hair thinning in the crown area associated with trichoscopic and histopathological features of LPP and were diagnosed with fibrosing alopecia in a pattern distribution (FAPD). Ten out of 188 patients $(5.3 \%)$ had lichenoid changes on the skin, mucous membranes and/or nails. The concomitant presence of AGA was found in 73 patients $(38.8 \%)$.

A family history of FFA was reported in 19 patients $(10.1 \%)$ with a mean age of onset at 56.4 years, while it was 59.6 years in patients without a family history $(\mathrm{P}=0.9)$.

Trichoscopy reports showed signs of cicatricial alopecia in all patients, with empty follicles in $93.6 \%$ of cases and absence of follicular ostia in $92 \%$ of cases. The presence of inflammatory signs such as perifollicular erythema and perifollicular hyperkeratosis were present in 129 (63.8\%) and $113(60.1 \%)$ of the patients, respectively. One hundred and three patients $(54.8 \%)$ presented lonely hairs. Trichoscopic signs were not associated with the degree of disease, but clinical signs of inflammation such as perifollicular erythema and perifollicular hyperkeratosis were associated with the presence of pruritus $(\mathrm{P}=0.049)$. Indeed, 124 patients $(65.9 \%)$ complained of itching and $43(22.9 \%)$ reported concomitant trichodynia.

In most cases $(71.8 \%)$, the characteristic clinical presentation (Figure 1) and the typical trichoscopic findings (Figure 2) made it possible to make the diagnosis of FFA without resorting to the use of invasive diagnostic techniques. Only 53 patients required a histopathological diagnosis.

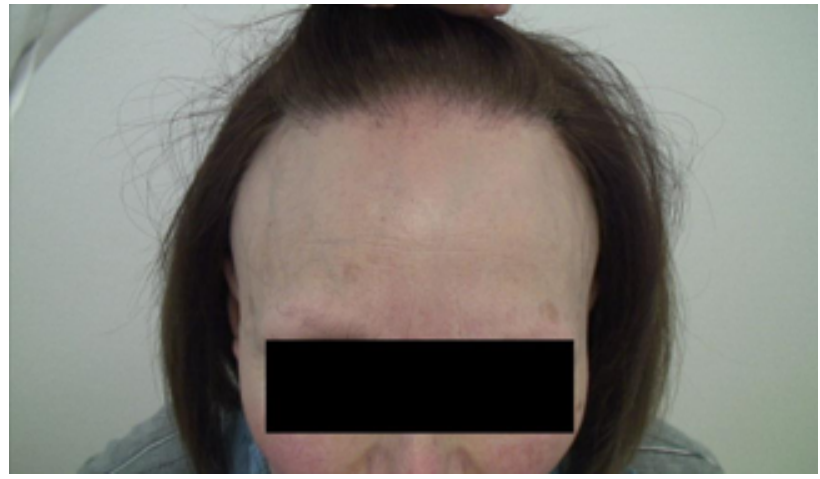

Figure 1. Clinical presentation of a female with frontal fibrosing alopecia.

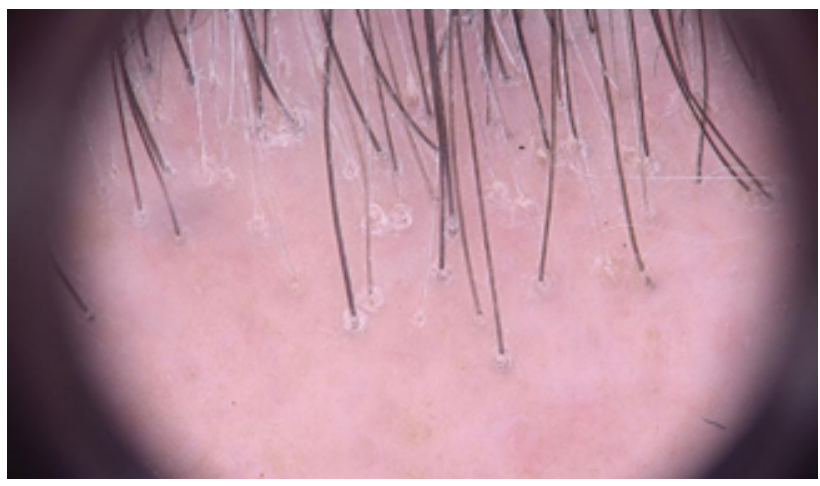

Figure 2. Trichoscopy of a female affected by frontal fibrosing alopecia.

The literature search identified a total of 24 papers (all published between 2014 and 2021) with more than 100 included cases (Table 2) [19, 25-27, 30-49]. During 2014, 2015 , and 2016 only one study was published per year $[25,48,49]$. Two and 5 studies were published in 2017 and

Table 2. Data of Published Studies on FFA Reporting more than 100 Cases

\begin{tabular}{|l|l|l|l|l|l|}
\hline $\begin{array}{l}\text { Pumber } \\
\text { of } \\
\text { patients }\end{array}$ & $\begin{array}{c}\text { Sex } \\
\text { M/F }\end{array}$ & \multicolumn{1}{|c|}{ Population } & Type of diagnosis & \multicolumn{1}{|c|}{ Data collected } \\
\hline $\begin{array}{l}\text { Muller Ramos P } \\
\text { et al 2021 [31] }\end{array}$ & 451 & $18 / 433$ & Brazil & $\begin{array}{l}\text { Clinical } \\
\text { (histopathological } \\
\text { when needed) }\end{array}$ & $\begin{array}{l}\text { Retrospective observational study } \\
\text { on effectiveness of dutasteride in } \\
\text { FFA }\end{array}$ \\
\hline $\begin{array}{l}\text { Grassi S } \\
\text { et al 2021 [32] }\end{array}$ & 224 & Spain & NA & $\begin{array}{l}\text { Multicenter case-control study on } \\
\text { risk factors for FFA }\end{array}$ \\
\hline $\begin{array}{l}\text { Trager MH } \\
\text { et al 2021 [33] }\end{array}$ & 173 & $14 / 159$ & Colombia and USA & $\begin{array}{l}\text { Clinical and } \\
\text { histopathological }\end{array}$ & $\begin{array}{l}\text { Retrospective observational } \\
\text { monocentric study on epidemiology, } \\
\text { clinical and trichoscopic features } \\
\text { and comorbidities in FFA patients }\end{array}$ \\
\hline $\begin{array}{l}\text { McSweeney SM } \\
\text { et al 2020 [34] }\end{array}$ & 711 & $0 / 711$ & UK & $\begin{array}{l}\text { Italy } \\
\text { distribution among patients with } \\
\text { LPP and FFA }\end{array}$ \\
\hline
\end{tabular}


Table 2. Data of Published Studies on FFA Reporting more than 100 Cases (continued).

\begin{tabular}{|c|c|c|c|c|c|}
\hline & $\begin{array}{l}\text { Number } \\
\text { of } \\
\text { patients }\end{array}$ & $\begin{array}{l}\text { Sex } \\
\text { M/F }\end{array}$ & Population & Type of diagnosis & Data collected \\
\hline $\begin{array}{l}\text { Anzai A } \\
\text { et al } 2019 \text { [27] }\end{array}$ & 151 & $0 / 151$ & Brazil/Italy & Histopathological & $\begin{array}{l}\text { Retrospective and prospective study } \\
\text { on trichoscopic findings of FFA of } \\
\text { the eyebrows }\end{array}$ \\
\hline $\begin{array}{l}\text { Papanikou S } \\
\text { et al } 2019[35]\end{array}$ & 100 & $0 / 100$ & Greece & NA & $\begin{array}{l}\text { Observational study on the influence } \\
\text { of social status on the prognosis of } \\
\text { FFA in female patients }\end{array}$ \\
\hline $\begin{array}{l}\text { Mulinari Brenner } \\
\text { F et al } 2019[36]\end{array}$ & 227 & NA & Brazil & NA & $\begin{array}{l}\text { Observational study on reported } \\
\text { cases of FFA in a tertiary center }\end{array}$ \\
\hline $\begin{array}{l}\text { Vañó-Galván et al } \\
2019 \text { [37] }\end{array}$ & 306 & NA & $\begin{array}{l}\text { Australia, Brazil, } \\
\text { Chile, Colombia, } \\
\text { Italy, Mexico, } \\
\text { Norway, Poland, } \\
\text { Portugal, South } \\
\text { Africa, Spain, } \\
\text { Switzerland, } \\
\text { USAand UK }\end{array}$ & NA & $\begin{array}{l}\text { Retrospective multicenter study on } \\
\text { frequencies of alopecia types at } 22 \\
\text { specialized hair clinics }\end{array}$ \\
\hline $\begin{array}{l}\text { Kanti V } \\
\text { et al } 2019[38]\end{array}$ & 490 & $25 / 465$ & $\begin{array}{l}\text { France and } \\
\text { Germany }\end{array}$ & $\begin{array}{l}\text { Clinical } \\
\text { (histopathological } \\
\text { when needed) }\end{array}$ & $\begin{array}{l}\text { Observational cross-sectional } \\
\text { descriptive study on demographic } \\
\text { and clinical characteristics } \\
\text { associated with the severity of FFA }\end{array}$ \\
\hline $\begin{array}{l}\text { Moreno-Arrones } \\
\text { OM } \\
\text { et al } 2019 \text { [39] }\end{array}$ & 278 & $0 / 278$ & Spain & $\begin{array}{l}\text { Clinical } \\
\text { (histopathological } \\
\text { when needed) }\end{array}$ & $\begin{array}{l}\text { Multicenter cross-sectional study on } \\
\text { factors influencing FFA severity }\end{array}$ \\
\hline $\begin{array}{l}\text { Tziotzios C } \\
\text { et al } 2019 \text { [19] }\end{array}$ & 1016 & $0 / 1016$ & Greece and UK & $\mathrm{NA}$ & $\begin{array}{l}\text { Genome-wide association study on } \\
\text { FFA }\end{array}$ \\
\hline $\begin{array}{l}\text { Moreno-Arrones } \\
\text { OM } \\
\text { et al } 2019[40]\end{array}$ & 335 & $20 / 315$ & Spain & NA & $\begin{array}{l}\text { Multicenter case-control study on } \\
\text { risk factors associated with FFA }\end{array}$ \\
\hline $\begin{array}{l}\text { Cranwell WC } \\
\text { et al } 2019 \text { [41] }\end{array}$ & 130 & $0 / 130$ & Australia & NA & $\begin{array}{l}\text { Case-control questionnaire study on } \\
\text { exposure to sunscreen or facial skin } \\
\text { care products and their association } \\
\text { with FFA }\end{array}$ \\
\hline $\begin{array}{l}\text { Buendia-Castano } \\
\text { D et al } 2018 \text { [42] }\end{array}$ & 104 & $0 / 104$ & Spain & $\begin{array}{l}\text { Clinical } \\
\text { (histopathological } \\
\text { when needed) }\end{array}$ & $\begin{array}{l}\text { Case-control study on hormonal } \\
\text { and gynecological risk factors for } \\
\text { FFA }\end{array}$ \\
\hline $\begin{array}{l}\text { Imhof RL } \\
\text { et al } 2018 \text { [43] }\end{array}$ & 148 & $0 / 148$ & USA & $\begin{array}{l}\text { Clinical } \\
\text { (histopathological } \\
\text { when needed) }\end{array}$ & $\begin{array}{l}\text { Retrospective study on } \\
\text { clinicopathological findings, } \\
\text { comorbidities and treatment } \\
\text { outcomes in women with FFA }\end{array}$ \\
\hline $\begin{array}{l}\text { Saceda-Corralo D } \\
\text { et al } 2018[44]\end{array}$ & 103 & $0 / 103$ & Spain & $\begin{array}{l}\text { Clinical } \\
\text { (histopathological } \\
\text { when needed) }\end{array}$ & $\begin{array}{l}\text { Descriptive cross-sectional study on } \\
\text { patients diagnosed with both FFA } \\
\text { and LPP }\end{array}$ \\
\hline $\begin{array}{l}\text { Cervantes J } \\
\text { et al } 2018 \text { [26] }\end{array}$ & 108 & NA & USA & $\begin{array}{l}\text { Clinical } \\
\text { (histopathological } \\
\text { when needed) }\end{array}$ & $\begin{array}{l}\text { Retrospective study on trichoscopic } \\
\text { features of sideburns in FFA } \\
\text { compared to fronto-temporal scalp }\end{array}$ \\
\hline $\begin{array}{l}\text { Pindado Ortega C } \\
\text { et al } 2018 \text { [45] }\end{array}$ & 103 & $0 / 103$ & Spain & $\begin{array}{l}\text { Clinical } \\
\text { (histopathological } \\
\text { when needed) }\end{array}$ & $\begin{array}{l}\text { Descriptive cross-sectional study } \\
\text { on relationship between FFA and } \\
\text { rosacea }\end{array}$ \\
\hline $\begin{array}{l}\text { Donati A } \\
\text { et al } 2017 \text { [46] }\end{array}$ & 149 & NA & France & $\begin{array}{l}\text { Clinical } \\
\text { (histopathological } \\
\text { when needed) }\end{array}$ & $\begin{array}{l}\text { Retrospective analysis on the use of } \\
\text { direct immunofluorescence in FFA }\end{array}$ \\
\hline
\end{tabular}


Table 2. Data of Published Studies on FFA Reporting more than 100 Cases (continued).

\begin{tabular}{|l|l|l|l|l|l|}
\hline & $\begin{array}{l}\text { Number } \\
\text { of } \\
\text { patients }\end{array}$ & $\begin{array}{c}\text { Sex } \\
\text { M/F }\end{array}$ & \multicolumn{1}{|c|}{ Population } & Type of diagnosis & \multicolumn{1}{|c|}{ Data collected } \\
\hline $\begin{array}{l}\text { Moreno Arrones } \\
\text { OM et al } 2017 \\
\text { [47] }\end{array}$ & 242 & $0 / 242$ & Spain & $\begin{array}{l}\text { Clinical } \\
\text { (histopathological } \\
\text { when needed) }\end{array}$ & $\begin{array}{l}\text { Retrospective single-centre } \\
\text { observational study on clinical and } \\
\text { prognostic classification of FFA }\end{array}$ \\
\hline $\begin{array}{l}\text { Aldoori N } \\
\text { et al 2016 [48] }\end{array}$ & 105 & $0 / 105$ & UK & Clinical & $\begin{array}{l}\text { Case-control study on the role of } \\
\text { leave-on facial skin care products } \\
\text { and sunscreen in FFA }\end{array}$ \\
\hline $\begin{array}{l}\text { Fernandez- } \\
\text { Crehuet P et al } \\
2015 \text { [25] }\end{array}$ & 249 & $11 / 238$ & Spain & $\begin{array}{l}\text { Clinical and } \\
\text { histopathological }\end{array}$ & $\begin{array}{l}\text { Descriptive retrospective } \\
\text { observational multicenter study on } \\
\text { trichoscopic features of FFA }\end{array}$ \\
\hline $\begin{array}{l}\text { Vañó-Galván et al } \\
2014 \text { [49] }\end{array}$ & 355 & $12 / 343$ & Spain & $\begin{array}{l}\text { Clinical } \\
\text { (histopathological } \\
\text { when needed) }\end{array}$ & $\begin{array}{l}\text { Retrospective multicenter study on } \\
\text { epidemiology, comorbidities, clinical } \\
\text { presentation, diagnostic findings, } \\
\text { and therapeutic choices in FFA }\end{array}$ \\
\hline
\end{tabular}

$\mathrm{FFA}=$ frontal fibrosing alopecia; $\mathrm{F}=$ females; $\mathrm{M}=$ ales; $\mathrm{NA}=$ not applicable.

2018, respectively [26,42-47]. Nine studies were released in 2019 [19,27,35-41] and 5 studies were published in 2020 and 2021 [30-34]. In 13 studies, clinical and trichoscopic features were decisive for the diagnosis in almost all FFA cases [26,30,34,39,42-49]. Invasive biopsies for histopathological examinations were reserved for doubtful cases and confirmed the diagnosis in all cases.

\section{Conclusions}

Since its first description in 1994, FFA has shown a significant increase in incidence all over the world. In 2014, Vañó-Galván et al published the first large cohort of patients diagnosed with FFA [49]. Subsequently, as confirmed by our review of the literature, the number of published large cohort studies have increased over time, in particular during the last 3 years. Of note, Tziotzios et al published the largest cohort study in 2019, reporting more than 1,000 patients from Greece and UK [19]. Here, we report an additional large cohort of patients diagnosed with FFA collected through IDS members who responded to our online call.

The mean age at onset of the disease in our sample was 58.6 years, which is comparable to the previously reported data on FFA. The results support the current theory that the disease mainly affects postmenopausal women $(88.1 \%)$, but also documents that it can be found in younger women $(11.9 \%)$. The youngest patient was 15 years old at the onset of symptoms. Our sample also included 3 male subjects supporting the fact that FFA can affect males as well. Cases of FFA within multiple members of the same family have been reported in $5-8 \%$ of the cases $[49,50]$, a result that is a very similar to the percentage observed in our study $(10.1 \%)$.
Navarro Belmonte et al reported that the age at onset of the disease in cases with relatives affected by FFA appears to be lower than in isolated cases [51]. Our study also showed an earlier onset of about 3 years in subjects with a positive family history. However, the difference between the two groups was not significant in our cases.

In accordance with other small studies [8,52], our study reported an association between FFA and LPP (18.6\% of cases) including 5 patients with FAPD. This observation supports the theory that FFA could actually represent a clinical variant of LPP despite the different symptoms. Although this association was not reported in larger studies, it is possible that it is under-reported.

Consistent with previous studies [53,54], the presence of AGA was recorded in $38.8 \%$ of patients suggesting that AGA may be at the root of a fibrotic process leading to FFA or that FFA and AGA may have a similar underlying pathogenetic mechanism, for example a hormonal basis. The role of hormones is however still uncertain and debated as well as the link between FFA, LPP and AGA. One retrospective study associated FFA with androgen deficiency, while LPP was more frequently associated with androgen excess [54]. Furthermore, no association with Lupus and AA was reported in our group of patients.

Interestingly, the diagnosis of FFA in our cohort was made on average 4.4 years after the onset of the disease and in $51.6 \%$ of cases already presented as grade 2 of severity with a mean frontal hairline recession of $2.35 \mathrm{~cm}$, which in some cases reached $10 \mathrm{~cm}$. This underlines the importance of awareness and education on this disease, not only among patients but also among health professionals, in order to diagnose and treat FFA at an earlier stage to stop the scarring process. 
Alopecia of the eyebrows, found in $85.6 \%$ of cases, was confirmed as the most frequent sign of the disease, while the loss of eyelashes and axillary, pubic and/or body hair was documented with a lower rate. Some authors have raised the doubt that the peripheral involvement of the disease could actually be simply a consequence of menopause and/or aging [55]. In this regard, we compared patients of childbearing age with menopausal patients and found overlapping percentages of body hair involvement in both age groups $(86.4 \%$ versus $87.1 \%$ ). Therefore, these observations seem to confirm the frequent involvement of various anatomical regions of FFA. In particular, eyebrow involvement could play a significant role in early diagnosis since, in many cases, thinning or loss of the eyebrows precedes the recession of the fronto-temporal hairline. Eyebrows and body hair reduction/loss are often confused with age-related loss and seldom reported by patients themselves. Thus, awareness of this sign possibly indicating FFA is important when considering differential diagnoses such as AA or aging [56]. Moreover, the finding of non-inflammatory facial papules was described in $29.8 \%$ of patients, suggesting that this sign should always be sought in cases of suspected FFA.

Even if the clinical diagnosis is most often easy to perform, trichoscopy is a valid aid in milder cases and in evaluation of facial/body hair loss. Trichoscopy is also a valid aid in the differential diagnosis with other diseases such as AGA, traction alopecia or AA in which there is no scarring. Interestingly, trichoscopic cicatricial signs were absent in a small percentage of patients, suggesting that FFA could likely begins as a non-scarring process. Consequently, early treatment could partially recover damaged follicles.

The presence of inflammatory signs such as perifollicular erythema and perifollicular hyperkeratosis were present in $63.8 \%$ and $60.1 \%$ of patients, respectively, and were associated with the presence of dysaesthetic sensations such as trichodynia and pruritus $(\mathrm{P}=0.049)$. Previous studies report that up to one-third of patients with FFA may have itching and, less frequently, trichodynia. However, our series revealed higher percentages of symptomatic subjects with $65.9 \%$ of patients complaining of itching and $22.9 \%$ reporting concomitant trichodynia.

In most cases $(71.8 \%)$ the characteristic clinical presentation and the typical trichoscopic findings allowed the diagnosis of FFA. The relevant role of the clinical and trichoscopic features in performing the diagnosis was also confirmed by the literature review. Indeed, in most studies they were decisive for the diagnosis confirming that trichoscopy is a worldwide-acknowledged non-invasive technique for the diagnosis of FFA. Further studies are necessary to evaluate the role of other in vivo non-invasive imaging techniques such as reflectance confocal microscopy, optical coherence tomography, diffuse reflection spectrophotometry and ultrasound in the investigation of FFA to reduce the need of surgical biopsies and histopathological confirmation of the disease.

\section{References}

1. Kossard S. Postmenopausal frontal fibrosing alopecia. Scarring alopecia in a pattern distribution. Arch Dermatol. 1994;130(6):770774.

2. Kossard S, MS Lee, B Wilkinson. Postmenopausal frontal fibrosing alopecia: a frontal variant of lichen planopilaris. J Am Acad Dermatol. 1997;36(1):59-66. DOI: 10.1016/s0190-9622(97)703268. PMID: 8996262.

3. Tziotzios C, Stefanato CM, Fenton DA, Simpson MA, McGrath JA. Frontal fibrosing alopecia: reflections and hypotheses on aetiology and pathogenesis. Exp Dermatol. 2016;25(11):847-852. DOI: 10.1111/exd.13071. PMID: 27198858.

4. Photiou L, Nixon RL, Tam M, Green J, Yip L. An update of the pathogenesis of frontal fibrosing alopecia: What does the current evidence tell us? Australas J Dermatol. 2019 May;60(2):99-104. DOI: 10.1111/ajd.12945. PMID: 30362109.

5. Kossard S. Frontal fibrosing alopecia, just lichen planopilaris? J Am Acad Dermatol. 2019;81(2):e51. DOI: 10.1016/j. jaad.2019.02.072. PMID: 30978423.

6. Bernárdez C, Molina-Ruiz AM, Vañó-Galvan S, et al. Sex hormone status in premenopausal women with frontal fibrosing alopecia: a multicentre review of 43 patients. Clin Exp Dermatol. 2017;42(8):921-923. DOI: 10.1111/ced.13221. PMID: 28940746.

7. Alegre-Sánchez A, Saceda-Corralo D, Bernárdez C, Molina-Ruiz AM, Arias-Santiago S, Vañó-Galván S. Frontal fibrosing alopecia in male patients: a report of 12 cases. J Eur Acad Dermatol Venereol. 2017;31(2):e112-e114. DOI: 10.1111/jdv.13855. PMID: 27505452.

8. Starace M, Brandi N, Alessandrini A, Bruni F, Piraccini BM. Frontal fibrosing alopecia: a case series of 65 patients seen in a single Italian centre. J Eur Acad Dermatol Venereol. 2019;33(2):433438. DOI: 10.1111/jdv.15372. PMID: 30472804.

9. Pirmez R, Duque-Estrada B, Abraham LS, et al. It's not all traction: the pseudo 'fringe sign' in frontal fibrosing alopecia. $\mathrm{Br} J$ Dermatol. 2015;173(5):1336-8. DOI: 10.1111/bjd.14005. PMID: 26138941.

10. Guan NN, Fan WX. Diagnostic and therapeutic assessment of frontal fibrosing alopecia. J Clin Dermatology. 2010;39(3):195197. DOI:10.1016/S1578-2190(07)70524-3.

11. Banka N, Mubki T, Bunagan MJ, McElwee K, Shapiro J. Frontal fibrosing alopecia: a retrospective clinical review of 62 patients with treatment outcome and long-term follow-up. Int J Dermatol. 2014;53(11):1324-1330. DOI: 10.1111/ijd.12479. PMID: 24738979.

12. Imhof R, Tolkachjov SN. Optimal Management of Frontal Fibrosing Alopecia: A Practical Guide. Clin Cosmet Investig Dermatol. 2020;13:897-910. DOI: 10.2147/CCID.S235980. PMID: 33293846 ; PMCID: PMC7718862.

13. Mulinari-Brenner FA, Guilherme MR, Peretti MC, Werner B. Frontal fibrosing alopecia and lichen planus pigmentosus: diagnosis and therapeutic challenge. An Bras Dermatol. 2017;92(5 Suppl 1):79-81. DOI: 10.1590/abd1806-4841.20175833. PMID: 29267454; PMCID: PMC5726685.

14. Requena L. Update on Frontal Fibrosing Alopecia. Actas Dermosifiliogr. 2017;108(4):293-304. DOI: 10.1016/j.ad.2016.11.012. PMID: 28117051. 
15. López-Pestaña A, Tuneu A, Lobo C, Ormaechea N, Zubizarreta J, Vildosola S, Del Alcazar E. Facial lesions in frontal fibrosing alopecia (FFA): Clinicopathological features in a series of 12 cases. J Am Acad Dermatol. 2015;73(6):987.e1-6. DOI: 10.1016/j. jaad.2015.08.020. PMID: 26432059

16. Mirmirani P, Tosti A, Goldberg L, Whiting D, Sotoodian B. Frontal Fibrosing Alopecia: An Emerging Epidemic. Skin Appendage Disord. 2019;5(2):90-93. DOI: 10.1159/000489793. PMID: 30815440; PMCID: PMC6388564.

17. Dlova N, Goh CL, Tosti A. Familial frontal fibrosing alopecia. Br J Dermatol. 2013;168(1):220-222. DOI: 10.1111/j.13652133.2012.11101.x. PMID: 22716508.

18. Tziotzios C, Fenton DA, Stefanato CM, McGrath JA. Familial frontal fibrosing alopecia. J Am Acad Dermatol. $2015 \mathrm{Ju}$ 1;73(1):e37. DOI: 10.1016/j.jaad.2015.01.057. PMID: 26089074.

19. Tziotzios C, Petridis C, Dand N, et al. Genome-wide association study in frontal fibrosing alopecia identifies four susceptibility loci including HLA-B*07:02. Nat Commun. 2019;10(1):1150. DOI: 10.1038/s41467-019-09117-w. PMID: 30850646; PMCID: PMC6408457.

20. Fernandez-Flores A. Frontal pseudoalopecia in history: Part 1Fashionable forms. Clin Dermatol. 2012;30(5):548-552. DOI: 10.1016/j.clindermatol.2011.08.003. PMID: 22902229.

21. Olsen EA, Harries M, Tosti A, et al. Guidelines for Clinical Trials of Frontal Fibrosing Alopecia: Consensus Recommendations from the International FFA Cooperative Group (IFFACG). $\mathrm{Br} J$ Dermatol. 2021. DOI: 10.1111/bjd.20567. Epub ahead of print. PMID: 34105768.

22. Iorizzo M, Tosti A. Frontal Fibrosing Alopecia: An Update on Pathogenesis, Diagnosis, and Treatment. Am J Clin Dermatol. 2019;20(3):379-390. DOI: 10.1007/s40257-019-00424-y. PMID: 30659454.

23. Gálvez-Canseco A, Sperling L. Lichen planopilaris and frontal fibrosing alopecia cannot be differentiated by histopathology. $J$ Cutan Pathol. 2018;45(5):313-317. DOI: 10.1111/cup.13112. PMID: 29369400.

24. Thompson CT, Tosti A. A method for more precise sampling of the scalp and eyebrows in frontal fibrosing alopecia. J Am Acad Dermatol. 2019;80(6):e155-e156. DOI: 10.1016/j.jaad.2018.12.033. PMID: 30586611.

25. Fernández-Crehuet $P$, Rodrigues-Barata AR, et al. Trichoscopic features of frontal fibrosing alopecia: results in 249 patients. J Am Acad Dermatol. 2015;72(2):357-359. DOI: 10.1016/j. jaad.2014.10.039. PMID: 25592346.

26. Cervantes J, Miteva M. Distinct Trichoscopic Features of the Sideburns in Frontal Fibrosing Alopecia Compared to the Frontotemporal Scalp. Skin Appendage Disord. 2018;4(1):50-54. DOI: 10.1159/000479116. PMID: 29457017; PMCID: PMC5806192.

27. Anzai A, Pirmez R, Vincenzi C, Fabbrocini G, Romiti R, Tosti A. Trichoscopy findings of frontal fibrosing alopecia on the eyebrows: A study of 151 cases. J Am Acad Dermatol. 2021;85(5):11301134. DOI: 10.1016/j.jaad.2019.12.023. PMID: 31857108.

28. Kurzeja M, Czuwara J, Walecka I, Olszewska M, Rudnicka L. Features of classic lichen planopilaris and frontal fibrosing alopecia in reflectance confocal microscopy: A preliminary study. Skin Res Technol. 2021;27(2):266-271. DOI: 10.1111/srt.12940. PMID: 32743819.

29. Vazquez-Herrera NE, Eber AE, Martinez-Velasco MA, et al. Optical coherence tomography for the investigation of frontal fibrosing alopecia. J Eur Acad Dermatol Venereol. 2018;32(2):318-322. DOI: $10.1111 /$ jdv.14571. PMID: 28859221.
30. Pindado-Ortega C, Saceda-Corralo D, Moreno-Arrones ÓM, et al. Effectiveness of dutasteride in a large series of patients with frontal fibrosing alopecia in real clinical practice. J Am Acad Dermatol. 2021;84(5):1285-1294. DOI: 10.1016/j.jaad.2020.09.093. PMID: 33038469.

31. Ramos PM, Anzai A, Duque-Estrada B, et al. Risk factors for frontal fibrosing alopecia: A case-control study in a multiracial population. J Am Acad Dermatol. 2021;84(3):712-718. DOI: 10.1016/j.jaad.2020.08.076. PMID: 32835739.

32. McSweeney SM, Christou EAA, Dand N, et al. Frontal fibrosing alopecia: a descriptive cross-sectional study of 711 cases in female patients from the UK. Br J Dermatol. 2020;183(6):1136-1138. DOI: 10.1111/bjd.19399. PMID: 32652611.

33. Trager MH, Lavian J, Lee EY, et al. Medical comorbidities and sex distribution among patients with lichen planopilaris and frontal fibrosing alopecia: A retrospective cohort study. J Am Acad Dermatol. 2021;84(6):1686-1689. DOI: 10.1016/j.jaad.2020.08.015. PMID: 32781188.

34. Grassi S, Tadiotto Cicogna G, et al. Frontal fibrosing alopecia and genital Lichen sclerosus: Single-center experience. J Cosmet Dermatol. 2021;20(2):615-620. DOI: 10.1111/jocd.13573. PMID: 32590887.

35. Papanikou S, Xydeas-Kikemenis A, Nicolaidou E, et al. Social Status May Interfere in the Prognosis of Frontal Fibrosing Alopecia in Female Patients: An Observational Study. Skin Appendage Disord. 2019;5(6):355-358. DOI: 10.1159/000501888. PMID: 31799262 ; PMCID: PMC6883467.

36. Brenner FM, Oldoni C. Frontal fibrosing alopecia: epidemic? An Bras Dermatol. 2019;94(4):482. DOI: 10.1590/abd18064841.20198300. PMID: 31644628; PMCID: PMC7007025.

37. Vañó-Galván S, Saceda-Corralo D, Blume-Peytavi U, et al. Frequency of the Types of Alopecia at Twenty-Two Specialist Hair Clinics: A Multicenter Study. Skin Appendage Disord. 2019 Aug;5(5):309-315. DOI: 10.1159/000496708. PMID: 31559256; PMCID: PMC6751437.

38. Kanti V, Constantinou A, Reygagne P, Vogt A, Kottner J, Blume-Peytavi U. Frontal fibrosing alopecia: demographic and clinical characteristics of 490 cases. J Eur Acad Dermatol Venereol. 2019;33(10):1976-1983. DOI: 10.1111/jdv.15735. PMID: 31179579.

39. Moreno-Arrones OM, Saceda-Corralo D, Rodrigues-Barata AR, et al. Factors influencing frontal fibrosing alopecia severity: a multicentre cross-sectional study. J Eur Acad Dermatol Venereol. 2019;33(9):e315-e316. DOI: 10.1111/jdv.15590. PMID: 30895660.

40. Moreno-Arrones OM, Saceda-Corralo D, Rodrigues-Barata AR, et al. Risk factors associated with frontal fibrosing alopecia: a multicentre case-control study. Clin Exp Dermatol. 2019;44(4):404410. DOI: 10.1111/ced.13785. PMID: 30259544.

41. Cranwell WC, Sinclair R. Sunscreen and facial skincare products in frontal fibrosing alopecia: a case-control study. Br J Dermatol. 2019;180(4):943-944. DOI: 10.1111/bjd.17354. PMID: 30367472.

42. Buendía-Castaño D, Saceda-Corralo D, Moreno-Arrones OM, et al. Hormonal and Gynecological Risk Factors in Frontal Fibrosing Alopecia: A Case-Control Study. Skin Appendage Disord. 2018;4(4):274-276. DOI: 10.1159/000484210. PMID: 30410895; PMCID: PMC6219213.

43. Imhof RL, Chaudhry HM, Larkin SC, Torgerson RR, Tolkachjov SN. Frontal Fibrosing Alopecia in Women: The Mayo Clinic Experience With 148 Patients, 1992-2016. Mayo Clin Proc. 
2018;93(11):1581-1588. DOI: 10.1016/j.mayocp.2018.05.036. PMID: 30392542.

44. Saceda-Corralo D, Fernández-Crehuet P, Fonda-Pascual P, Pindado-Ortega C, Moreno-Arrones OM, Vañó-Galván S. Clinical Description of Frontal Fibrosing Alopecia with Concomitant Lichen Planopilaris. Skin Appendage Disord. 2018;4(2):105-107. DOI: 10.1159/000479799. PMID: 29765970; PMCID: PMC5939712.

45. Pindado-Ortega C, Saceda-Corralo D, Buendía-Castaño D, et al. Frontal fibrosing alopecia and cutaneous comorbidities: A potential relationship with rosacea. J Am Acad Dermatol. 2018;78(3):596-597.e1. DOI: 10.1016/j.jaad.2017.09.004. PMID: 29447678.

46. Donati A, Gupta AK, Jacob C, Cavelier-Balloy B, Reygagne P. The Use of Direct Immunofluorescence in Frontal Fibrosing Alopecia. Skin Appendage Disord. 2017;3(3):125-128. DOI: 10.1159/000469665. PMID: 28879188; PMCID: PMC5582472.

47. Moreno-Arrones OM, Saceda-Corralo D, Fonda-Pascual P, et al. Frontal fibrosing alopecia: clinical and prognostic classification. J Eur Acad Dermatol Venereol. 2017;31(10):1739-1745. DOI: 10.1111/jdv.14287. PMID: 28426907.

48. Aldoori N, Dobson K, Holden CR, McDonagh AJ, Harries M, Messenger AG. Frontal fibrosing alopecia: possible association with leave-on facial skin care products and sunscreens; a questionnaire study. Br J Dermatol. 2016;175(4):762-767. DOI: 10.1111/ bjd.14535. PMID: 26987767.

49. Vañó-Galván S, Molina-Ruiz AM, Serrano-Falcón C, et al. Frontal fibrosing alopecia: a multicenter review of 355 patients. J Am Acad Dermatol. 2014;70(4):670-678. DOI: 10.1016/j. jaad.2013.12.003. PMID: 24508293.
50. Dlova NC. Jordaan HF, Skenjane A, Khoza N, Tosti A. Frontal fibrosing alopecia: A clinical review of 20 black patients from South Africa. Br J Dermatol. 2013;169(4):939-941. DOI: 10.1111/ bjd.12424. PMID: 23647261.

51. Navarro-Belmonte MR, Navarro-López V, Ramírez-Boscà A, et al. Case series of familial frontal fibrosing alopecia and a review of the literature. J Cosmet Dermatol. 2015;14(1):64-9. DOI: 10.1111/jocd.12125. PMID: 25614294.

52. Ranasinghe GC, Piliang MP, Bergfeld WF. Prevalence of hormonal and endocrine dysfunction in patients with lichen planopilaris (LPP): A retrospective data analysis of 168 patients. J Am Acad Dermatol. 2017;76(2):314-320. DOI: 10.1016/j. jaad.2016.05.038. PMID: 28088992.

53. Samrao A, Chew AL, Price V. Frontal fibrosing alopecia: a clinical review of 36 patients. Br J Dermatol. 2010;163(6):1296-300. DOI: 10.1111/j.1365-2133.2010.09965.x. PMID: 20698851.

54. Moreno-Ramírez D, Camacho Martínez F. Frontal fibrosing alopecia: a survey in 16 patients. Eur Acad Dermatol Venereol. 2005;19(6):700-705. DOI: 10.1111/j.1468-3083.2005.01291.x. PMID: 16268874.

55. Ladizinski B, Bazakas A, Selim MA, Olsen EA. Frontal fibrosing alopecia: a retrospective review of 19 patients seen at Duke University. J Am Acad Dermatol. 2013;68(5):749-755. DOI: 10.1016/j.jaad.2012.09.043. PMID: 23375454.

56. Waśkiel-Burnat A, Rakowska A, Kurzeja M, et alL. The value of dermoscopy in diagnosing eyebrow loss in patients with alopecia areata and frontal fibrosing alopecia. J Eur Acad Dermatol Venereol. 2019;33(1):213-219. DOI: 10.1111/jdv.15279. PMID: 30290016. 